\title{
DERMEVAL SAVIANI - COMPROMISSO E LUTA POR UMA PEDAGOGIA PARA ALÉM DO CAPITAL
}

\author{
Eraldo Leme Batista ${ }^{1}$ \\ Marcos Roberto Lima ${ }^{2}$
}

\section{RESUMO}

Neste texto, discorreremos sobre a importância de Dermeval Saviani como intelectual de considerável envergadura teórica e de ação política na luta por uma educação para além da lógica do capital. Trata-se de um autor comprometido com a educação emancipadora, respondendo de forma dialética ao debate hodierno entre aqueles que desconsideram a educação escolar como espaço de luta, entendendo-a como um aparelho ideológico a serviço da ordem capitalista, e aqueles que, apesar de afirmarem defendê-la, apresentam propostas pedagógicas que impossibilitam uma formação omnilateral que possa servir de instrumento na superação da ordem capitalista. Saviani consolidou-se como um intelectual imprescindível para o pensamento pedagógico, social e político, sobretudo na virada do século XX, mantendo-se pertinente diante dos debates político-pedagógicos da atual etapa histórica, marcada ainda pelos efeitos da ofensiva neoliberal e a emergência do pensamento "pós-moderno". Como pensador engajado, esteve à frente de muitas lutas pela organização dos profissionais da educação, participando ativamente da criação de importantes organizações científicas e de luta dos educadores, como a Associação Nacional de Pós-Graduação e Pesquisa em Educação (ANPED), criada em 1977, tendo sido seu primeiro presidente. Em 1986, Saviani reuniu diversos educadores brasileiros por meio da criação do Grupo de Estudos e Pesquisas "História, Sociedade e Educação no Brasil” (HISTEDBR), do qual é atualmente coordenador geral. Tendo como principal contribuição teórica a pedagogia histórico-crítica, a pretensão maior do HISTEDBR é a articulação da pesquisa séria em educação às lutas mais gerais pela transformação da sociedade. Em setembro de 1999, foi fundada a Sociedade Brasileira de História da Educação (SBHE), tendo sido Saviani seu primeiro presidente. Sua contribuição é de tal relevância que ousamos dizer que não se compreende a filosofia da educação, a história da educação, a sociologia da educação, a política educacional e a estrutura do ensino no Brasil, básico ou superior, sem o estudo comprometido com as obras deste pensador.

Palavras-chave: Dermeval Saviani; educação emancipadora; pedagogia histórico-crítica.

\section{DERMEVAL SAVIANI - COMMITMENT AND STRUGGLE FOR EDUCATION BEYOND CAPITAL}

\begin{abstract}
Our paper discusses the importance of Dermeval Saviani as an intellectual of considerable theoretical scope and political action in the struggle for education beyond the logic of the capital. Dermeval Saviani is an author committed to emancipatory education who responds in a dialectic way to today's debate between those who disregard school education as a space of struggle and consider it an ideological apparatus in the service of the capitalist order and those who, despite the fact that they claim defending it, present pedagogical proposals that preclude omnilateral training that could be instrumental in overcoming the capitalist order. Saviani established himself as an imperative intellectual to pedagogical, social and political thought, especially at the turn of the twentieth century, and has remained relevant in the political and pedagogical debates of the current historical stage,
\end{abstract}


which is further marked by the effects of the neoliberal offensive and the emergence of "postmodern" thought. His contribution to the struggle for a (basic) and (higher) education that permits the formation of organic working class intellectuals is unquestionable. As an engaged thinker, he was at the forefront of many struggles for the organization of education professionals and actively participated in the creation of important scientific and educational organizations, such as the National Association of Graduate Studies and Research in Education (ANPED) created in 1977, where he served as its first president. In 1986, he gathered several Brazilian educators and created the Studies and Research Group "History, Society and Education in Brazil" (HISTEDBR), where he serves as its current general coordinator. The group's main aim is to link serious research in education to the broader struggles for the transformation of society. In September 1999, the Brazilian Society for the History of Education (SBHE) was founded, where Saviani served as its first president. His contribution is of such importance that we dare say that one cannot understand philosophy of education, history of education, sociology of education, educational politics, or the structure of basic and higher education in Brazil without the committed study to the works of that thinker.

Keywords: Dermeval Saviani; emancipatory education; historical-critical pedagogy.

\section{Dermeval Saviani, trajetória de luta e compromisso com a transformação social}

Discorrer sobre a trajetória de um pesquisador que se tornou um clássico do pensamento social e pedagógico no Brasil não é tarefa fácil. Assim sendo, pretendemos desenvolver breves apontamentos sobre a importância de Dermeval Saviani para a educação e o pensamento pedagógico brasileiro. Por se tratar de um autor de vasta e consagrada obra, uma abordagem cuja pretensão excedesse este intuito demandaria um trabalho mais extenso e com maior profundidade, o que não é a proposta do artigo ora apresentado.

\section{Resistência estudantil e fundamentação filosófica: intelectual e militante forjado na prática social}

Ao final da década de 1970 a repressão militar mantinha-se ainda forte no Brasil. Não sem a resistência dos movimentos de oposição ao regime, destacando-se as organizações da classe operária e camponesa. As ações políticas dos trabalhadores metalúrgicos do $\mathrm{ABC}$ foram fundamentais para o fortalecimento da luta contra a repressão e pela abertura política. Greves importantes foram deflagradas, acirrando o embate com as forças de repressão militar, incapazes de eliminar totalmente a oposição. Apoiados pelos estudantes no enfrentamento do projeto da burguesia nacional, sustentado nas ações truculentas do Estado e na aliança com o capital monopólico internacional, sobretudo estadunidense, os trabalhadores entraram em cena, paralisando a produção, abalando a hegemonia capitalista.

Mesmo sob a ferrenha perseguição dos militares, o movimento estudantil se articulou aos trabalhadores, a setores da classe média e parte da Igreja Católica ${ }^{1}$ na resistência à ditadura. Foi nesse período conturbado da história brasileira que Dermeval Saviani realizou seus estudos universitários na PUC-SP. Durante a graduação em Filosofia, realizada entre os anos de 1963 e 1966, foram sendo definidas as ideias que embasaram sua crítica às pedagogias conservadoras, sobretudo ao escolanovismo. Participando ativamente 
na luta estudantil, Saviani tornou-se defensor do socialismo, buscando sua fundamentação teórica nas obras de Marx, Engels, Lênin e Gramsci, além do rigoroso estudo dos principais clássicos da educação, sobretudo no campo do marxismo.

O compromisso com uma educação transformadora tem acompanhado toda a sua trajetória, não se desarticulando sua produção intelectual e prática docente da prática militante, o que se expressa no rigor técnico com que conduz o incansável trabalho educativo $^{2}$. Ainda que, assumindo os riscos provenientes de sua opção política, Saviani não cedeu em seus princípios na busca por uma proposta pedagógica que fizesse frente às pedagogias oficiais ${ }^{3}$, defensoras dos interesses burgueses.

Foi nesse contexto histórico que Saviani desenvolveu os fundamentos filosóficos que estruturaram suas teses no campo da pedagogia, questionando as teses conservadoras instauradas no meio educacional brasileiro. Na luta política contra a ditadura militar e seus aspectos educacionais, Saviani forjou sua importante contribuição para a educação brasileira, desenvolvendo uma teoria pedagógica voltada aos interesses e necessidades da classe trabalhadora, contrapondo-se às ideias liberais em educação.

\section{Uma proposta pedagógica das classes subalternas para a transformação social}

Do trabalho intelectual de Saviani surge uma proposta pedagógica transformadora que objetiva superar, por um lado, os limites da pedagogia tradicional e escolanovista e, por outro, a insuficiência da crítica realizada a estas últimas pelas teorias por ele classificadas como "crítico-reprodutivistas" (SAVIANI, 2009).

A primeira tentativa de sistematização do que viria a ser a pedagogia históricocrítica deu-se por meio de um artigo publicado em 1982, na revista ANDE, número 3, intitulado Escola e Democracia: para além da curvatura da vara. Em 1983, Saviani publicou o livro Escola e Democracia (idem), defendendo o saber sistematizado e a compreensão da realidade como instrumentos imprescindíveis para a transformação social.

Saviani deparou-se inicialmente com a dificuldade em atribuir à sua concepção pedagógica uma denominação adequada ao acúmulo teórico que o levara a criticar tanto o escolanovismo, quanto as teorias crítico-reprodutivistas, optando inicialmente pelo termo 'pedagogia dialética' (BATISTA \& LIMA, 2012, p. 15).

Saviani optou por um conceito que expressava o acúmulo teórico-prático de sua trajetória, qual seja "pedagogia histórico-crítica", justificando que:

[...] a expressão histórico-crítica traduzia de modo pertinente o que estava sendo pensado. Porque exatamente o problema das teorias críticoreprodutivistas era a falta de enraizamento histórico, isto é, a apreensão do movimento histórico que se desenvolve dialeticamente em suas contradições (SAVIANI, 2008, pp. 140-41).

Para Saviani, a denominação histórico-crítica contribuía para a superação dos limites da expressão "crítico-reprodutivista", deixando evidente seu enraizamento na história.

Em 1984, atendendo à demanda dos alunos do programa de pós-graduação em educação da PUC-SP, Saviani ministrou a disciplina pedagogia histórico-crítica, adotando definitivamente essa expressão para designar a corrente pedagógica que vem desenvolvendo de forma coletiva ${ }^{4}$, por meio da formação de várias gerações de pesquisadores que buscam nela um referencial teórico para a prática educativa.

A pedagogia histórico-crítica teve sua origem na necessidade de desenvolvimento de uma teoria pedagógica que possibilitasse aos educadores uma análise crítica da 
educação, inserindo-a nas contradições presentes na sociedade. Trata-se, portanto, de uma proposta pedagógica gestada a partir do contraponto ao modismo da Escola Nova e sua crença no poder de equalização social da escola, sem capitular, no entanto, ao caráter não dialético das "teorias crítico-reprodutivistas".

Atualmente, Saviani tem recebido críticas de setores marxistas que defendem não haver na pedagogia histórico-crítica uma perspectiva revolucionária. Como resposta, Saviani publicou recentemente em parceira com Newton Duarte um primoroso trabalho, intitulado Pedagogia histórico-crítica e luta de classes na educação escolar, destacando o vínculo desta perspectiva filosófica e educacional com a luta de classes (DUARTE; SAVIANI, 2012).

Nesta obra, assevera Saviani que a experiência histórica mostra:

[...] que a existência de uma situação de crise e mesmo o aparecimento de movimentos insurrecionais de massa em várias partes do mundo não são condições suficientes para a constituição de um movimento revolucionário socialista. Para tanto, é imprescindível a ação coletiva consciente e organizada, com estratégias objetivamente fundamentadas, em direção a uma reestruturação radical que promova a socialização da propriedade dos meios de produção. Se, por um lado, essa perspectiva não é absolutamente, como muitos pensam, uma utopia sem base real, por outro lado sua concretização não será resultado da ação de forças espontâneas (DUARTE; SAVIANI, 2012, pp. 1-2).

Saviani explora radicalmente a contradição entre a especificidade do trabalho educativo na escola, qual seja a socialização do conhecimento em suas formas mais desenvolvidas, e a apropriação privada do conhecimento, entendendo este último como parte constitutiva dos meios de produção que, sobre a égide do capital, não podem ser socializados.

A educação escolar se encontra em meio a um movimento contraditório que, por um lado, identificando-se com os interesses dominantes, postula à escola a realização de quase todas as funções, menos a de transmissão sistemática do conhecimento, a pretexto de serem respeitadas as diferenças culturais e o acesso espontâneo ao conhecimento assegurado pelas novas tecnologias da informação. Tal defesa oculta, no entanto, a verdadeira estratégia de adaptação dos indivíduos às condições de vida impostas pelas atuais transformações no mundo do trabalho. Por outro lado, esse movimento pode tomar outra direção, a: "[...] da luta pela efetivação da especificidade da escola, fazendo do trabalho de socialização do conhecimento o eixo central de tudo o que se realiza no interior dessa instituição" (idem, p. 3).

Esta última direção apontada exige a superação da espontaneidade, o que requer o desenvolvimento de ações organizadas no âmbito do embate político e a formação de quadros qualificados para a tarefa de: "[...] produzir direta e intencionalmente, em cada indivíduo singular, a humanidade que é produzida histórica e coletivamente pelo conjunto dos homens" (SAVIANI, 2008, p. 13).

Que fique claro, não se trata de uma forma de "fetichização" da escola, ou do saber, pois, como reconhece Saviani: “[...] Essa luta, por si mesma, não revolucionará a sociedade pelo simples fato de que a escola não tem o poder de mudar a sociedade" (DUARTE; SAVIANI, 2012, p. 4). O que também não significa incorrer em um fatalismo imobilista que pouco colabora para o processo de transformação da realidade concreta na qual está inserida a escola. 
da história":

Como observamos em obra anterior, Saviani apoia-se em uma "concepção dialética

[...] o que não permite pensar que as questões escolares são o limite de uma atuação pedagógica transformadora. A educação é entendida a partir de determinantes históricos que sobre ela incidem, não se limitando qualquer estratégia revolucionária ao tratamento isolado da escola (BATISTA \& LIMA, 2012, p. 24-25).

A proposta de uma educação revolucionária propugnada por Saviani tem como ponto de partida e ponto de chegada a prática social. Sendo assim, a pedagogia históricocrítica está fundamentada em cinco passos dialeticamente articulados:

1 - Prática social: ponto de partida da prática educativa comum a professor e alunos, apesar de serem agentes diferenciados. Afirma Saviani:

[...] o professor assim como os alunos pode posicionar-se diferentemente enquanto agentes sociais diferenciados. E do ponto de vista pedagógico há uma diferença essencial que não pode ser perdida de vista: o professor, de um lado, e os alunos, de outro, encontram-se em níveis diferentes de compreensão (conhecimento e experiência) da pratica social [...] A compreensão do professor é sintética porque implica certa articulação dos conhecimentos e das experiências que detém relativamente a pratica social. (SAVIANI, 2009, p. 63);

A prática social é o momento de compreensão das posições dos indivíduos diante dos conteúdos, momento em que se sonda, sendo, por isso, o ponto de partida do processo de aprendizagem. Não se deve confundir a defesa de uma relação democrática entre professor e alunos com a igualdade de ambos no processo educativo. Ao professor cabe orientar os alunos, envoltos numa pratica social cuja compreensão é caótica, fundamentada no senso comum, possibilitando-lhes a superação dos limites do conhecimento de experiência feito.

2 - Problematização: trata-se da diretriz que norteará o desenvolvimento dos conteúdos a serem trabalhados a partir da necessidade de compreensão da realidade na qual se insere a prática social. Assevera Saviani, contrapondo-se tanto à metodologia tradicional quanto aos métodos da pedagogia nova:

O segundo passo não seria apresentação de novos conhecimentos por parte do professor (pedagogia tradicional) nem o problema como um obstáculo que interrompe a atividade dos alunos (pedagogia nova). Caberia, nesse momento, a identificação dos principais problemas postos pela pratica social... Trata-se de detectar que questões precisam ser resolvidas no âmbito da pratica social, e em consequência, que conhecimento é necessário dominar. (SAVIANI, 2009, p. 64).

3 -Instrumentalização: correspondendo à aquisição daquilo que deve ser apropriado para a superação da posição subalterna, mediante a aquisição dos instrumentos teóricos necessários à compreensão da realidade e a solução dos problemas aos quais os homens se deparam em sua prática social. Explicita Saviani: 
Trata-se de apropriar-se dos instrumentos teóricos e práticos necessários ao equacionamento dos problemas detectados na prática social. Como tais instrumentos são produzidos socialmente e preservados historicamente, a sua apropriação pelos alunos está na dependência de sua transmissão direta ou indireta por parte do professor (idem).

É por meio dos conteúdos que corroboram para o conhecimento da realidade que o dominado terá condições de transpor-se ao dominante. O conteúdo não pode ser determinado pelo educando, posto que o objetivo específico do processo educativo é a transmissão e a apropriação dos conhecimentos clássicos externados através da prática social historicamente desenvolvida pelos homens no tempo. O momento em que o conteúdo é incorporado, podendo ser transposto pelo educando, correspondendo à sua internalização eficaz, o que corresponde ao quarto passo, ao qual Saviani denominou catarse.

4 - Catarse: adquiridos os instrumentos básicos, ainda que parcialmente, é chegado o momento da expressão elaborada da nova forma de entendimento da prática social a que se ascendeu. A catarse é entendida aqui na acepção gramsciana de "elaboração superior de estrutura em superestrutura na consciência dos homens" (GRAMSCI, 2006, p. 314). Tratase do ponto de partida para novas iniciativas, elaboradas de forma superior na consciência dos homens, que assim podem desenvolver uma prática social subsidiada pelos recursos teóricos necessários à ação transformadora.

5 - Prática social: ponto de chegada da prática educativa, distante agora da prática social da qual se partiu. O percurso transcorrido possibilitou ao professor conduzir o aluno ao ponto de problematização e instrumentalização em que ele próprio se encontra na abordagem dos conteúdos. $\mathrm{O}$ método torna-se, então, prática, possibilitando a transformação do próprio professor, enquanto o conteúdo é incorporado à prática social do aluno, distante agora do senso comum, alimentada pela consciência filosófica. Saviani assim ilustra essa passagem:

Nesse ponto, ao mesmo tempo que os alunos ascendem ao nível sintético em que, por suposto, já se sabe encontrava o professor no ponto de partida, reduz-se a precariedade da síntese do professor, cuja compreensão se torna mais e mais orgânica. Essa elevação dos alunos ao nível do professor é essencial para compreender-se a especificidade da relação pedagógica. Dai por que o momento catártico pode ser considerado o ponto culminante do processo educativo, já que é ai que se realiza, pela mediação da análise levada a cabo no processo de ensino, a passagem da síncrese à síntese. (SAVIANI, 2009, p. 65).

Segundo algumas vertentes pedagógicas o pensamento não se desenvolve através da aquisição do conhecimento, elemento central da prática educativa fundamentada na pedagogia histórico-crítica, mas sim, da prática cotidiana fundamentada na autonomia do aluno. A aquisição dos conteúdos escolares é dessa forma entendida como um processo estático que não proporciona autonomia aos indivíduos (educação bancária). Isso só seria possível se os conteúdos não tivessem atividade humana acumulada. No entanto, até mesmo os conteúdos menos desenvolvidos trazem em si tal atividade, que dirá os mais desenvolvidos. 


\section{A pedagogia histórico-crítica e a radicalização das necessidades: da cotidianidade alienada à consciência filosófica}

Para Marx, devemos partir das formas mais complexas para compreendermos as formas menos complexas de abstração, o que se expressa na seguinte assertiva: "[...] A anatomia do ser humano é uma chave para compreensão da anatomia do macaco" (MARX, 2011, p. 58). Assim sendo, para compreendermos as formas anteriores de civilização, precisamos partir da compreensão da sociedade burguesa, a mais desenvolvida forma de organização da produção.

É nessa passagem da Introdução à Crítica da Economia Política que Saviani encontra apoio para afirmar que a transmissão-assimilação do saber humano elaborado deve ter por referência o conteúdo que se consolidou como clássico. Tese essa subsidiada também por Gramsci, ao afirmar que: “[...] é necessário entrar na fase 'clássica', racional, encontrando nos fins a atingir a fonte natural para elaborar os métodos e as formas" (2006b, p. 39). Em outros termos:

[...] clássico na escola é a transmissão-assimilação do saber sistematizado. Este é o fim a atingir. É ai que cabe encontrar a fonte natural para elaborar os métodos e as formas de organização do conjunto das atividades da escola, isto é, do currículo. E aqui podemos recuperar o conceito abrangente de currículo: organização do conjunto das atividades nucleares distribuídas no espaço e tempo escolares. Um currículo é, pois, uma escola funcionando, quer dizer, uma escola desempenhando a função que lhe é própria (SAVIANI, 2008, p. 18).

A atividade em estado latente é incorporada à vida alunos, sendo por eles reproduzida a humanidade que é produzida coletiva e historicamente pelos homens, tratando-se de uma "reprodução" sobre novas bases.

A criança o faz de forma espontânea, pois a atividade humana está condensada na cultura, que produz nos indivíduos as capacidades e necessidades humanas. Os processos de aprendizagem dirigidos conscientemente pelo educador são de ordem superior. O ser humano nasce com necessidades limitadas, às quais são acrescentadas necessidades culturais qualitativamente superiores. A educação não deve satisfazer as necessidades dos alunos, mas radicalizá-las, produzindo neles "necessidades humanizadas", superando os limites da cotidianidade alienada (DUARTE, 2007, p. 58).

A busca pela superação da alienação presente na cotidianidade dos indivíduos aproxima a pedagogia histórico-crítica dos fundamentos desenvolvidos pela escola de Vigotski e sua psicologia histórico-cultural. Sobre essa identidade de objetivos, acrescenta Martins:

$\mathrm{Na}$ sociedade em que vivemos, universalizadora das relações de exploração do homem pelo homem, que usurpa da grande maioria das pessoas o direito a uma existência digna, a realidade, criada pelos próprios homens, não pode ser mero objeto de percepção, contemplação passiva e ação adaptativa. Preparar os indivíduos para seu controle e domínio demanda torná-la inteligível e objeto de ações transformadoras. Tais ações exigem, necessariamente, um tipo de pensamento que provoca a superação da empiria fetichizada, das aparências - sejam elas falsas ou verdadeiras -, instrumentalizando os indivíduos para a atividade consciente, para a transformação das circunstancias e de si mesmo. É com essa tarefa que entendemos a educação escolar verdadeiramente 
emancipadora, e a serviço dela colocam-se tanto a pedagogia históricocrítica quanto a psicologia histórico-cultural (2011, p. 56).

Não se trata do abandono das determinações de onde partem os indivíduos, mas de seu enriquecimento através da mediação da escola, que deve proporcionar a passagem do saber espontâneo ao saber sistematizado, da cultura popular à cultura erudita, pois:

[...] o acesso à cultura erudita possibilita a apropriação de novas formas por meio das quais se podem expressar os próprios conteúdos do saber popular. Cabe, pois, não perder de vista o caráter derivado da cultura erudita em relação à cultura popular, cuja primazia não é destronada. Sendo uma determinação que se acrescenta, a restrição do acesso à cultura erudita conferirá àqueles que dela se apropriam uma situação de privilégio, uma vez que o aspecto popular não lhes é estranho. A recíproca, porém, não é verdadeira: os membros da população marginalizados da cultura letrada tenderão a encará-la como uma potência estranha que os desarma e domina (SAVIANI, 2008, p. 22).

$\mathrm{O}$ acesso à cultura erudita, por questões estruturais distante do cotidiano dos subalternos, assim como aos instrumentos lógicos do pensamento, que não são inatos, mas adquiridos, deve ser um elemento central na prática escolar. Analogamente à prática inerente aos instrumentos de trabalho, esse tirocínio da lógica ao qual deve se propor a escola supera o saber de experiência feito próprio da cultura popular, uma vez que, como observa Gramsci:

[...] os modos de pensar são elementos adquiridos e não inatos, cuja posse corresponde a uma qualificação profissional. Não possuí-los, não dar-se conta de não possuí-los, não propor-se o problema de adquiri-los através de um aprendizado, equivale a querer construir um automóvel sabendo utilizar, e tendo à disposição, a oficina e as ferramentas de um ferreiro de aldeia (Cf. MANACORDA, 2008, p. 153).

Por outro lado, incorrer no distanciamento do elemento popular, não compreendendo suas paixões, de forma a explicá-las e justificá-las a partir de uma "situação histórica concreta" (GRAMSCI, 2006a, p. 221) levaria qualquer pedagogia, ainda que originária no campo da esquerda, a um enclausuramento intelectualista que pouco pode contribuir para a transformação social.

A pedagogia histórico-crítica se torna, assim, um instrumento contra-hegemônico luta na atual etapa histórica, marcada pelas transformações no mundo do trabalho, incidindo diretamente sobre a educação dos trabalhadores.

\section{O labirinto da reestruturação produtiva do capital e os desafios da pedagogia histórico-crítica: a centralidade do trabalho como princípio educativo}

Dentre as principais características da crise estrutural que se abateu sobre o mundo capitalista no início dos anos de 1970, destacam-se as transformações no mundo do trabalho. Como resposta à crise, intensificaram-se as mudanças na base produtiva, avançando as formas de acumulação flexível e os modelos alternativos ao binômio taylorismo/fordismo, destacando-se o chamado modelo toyotista ${ }^{5}$ (ANTUNES, 2002, p. 181). 
Forja-se uma nova sociabilidade a partir das transformações na base produtiva, fundamentada na alteração da materialidade da classe trabalhadora nas esferas subjetiva, política e ideológica, na qual se assentam suas ações e práticas concretas. Assim, o capital busca levar ao limite o envolvimento manipulatório dos trabalhadores, por meio de seu consentimento e adesão no interior das empresas (idem). Como observa Antunes:

Opondo-se ao contra-poder que emergia das lutas sociais, o capital iniciou um processo de reorganização das suas formas de dominação societal, não só procurando reorganizar em termos capitalistas o processo produtivo, mas procurando gestar um projeto de recuperação da hegemonia nas mais diversas esferas de sociabilidade (ANTUNES, 2005, p. 48).

O capital busca ocultar sua unidade sistêmica e lógica destruidora, bloqueando o acesso aos "conhecimentos totalizadores" e às grandes narrativas fundamentadas na noção de totalidade, sistema, estrutura e processo. A única grande narrativa aceita, em uníssono com a fragmentação e a contingência "pós-moderna", é a grande narrativa do fim da história (WOOD, 2006, p. 13).

Como observa Wood, a rejeição do conhecimento totalizador se constitui em uma estratégia de fuga do confronto por parte do capital, ao qual interessa mais a fragmentação e descentralização das lutas sociais das camadas subalternas. Como antídoto à estratégia "pós-moderna”, propõe a autora:

Em oposição a essa tendência dominante, proponho partir da premissa de que a crítica do capitalismo é urgentemente necessária, que o materialismo histórico ainda oferece a melhor base sobre a qual é possível construí-la e que o elemento crítico do marxismo está acima de tudo em sua insistência na especificidade histórica do capitalismo - com ênfase tanto na especificidade de sua lógica sistêmica quanto na sua historicidade. Em outras palavras, o materialismo histórico aborda o capitalismo de uma forma exatamente antitética às modas atuais: a unidade sistêmica do capitalismo em vez de meros fragmentos pósmodernos, mas também a historicidade - e daí a possibilidade de sua superação - e não a inevitabilidade capitalista e o fim da história (WOOD, 2006, p. 14).

Já no início dos anos de 1990, Saviani alertava para os efeitos da "pósmodernidade" no campo da educação. A escola é atingida diretamente pela crise cultural da atualidade, passando a ser vista como uma forma secundária de educação, afirmando-se que se educa através de outros espaços, como os sindicatos, o partido, a igreja, associações de mães, clubes de mães, clubes esportivos, convivência, meios de comunicação de massa (SAVIANI, 1991, p. 32).

Mas, qual seria a chave heurística para se desvendar o enigma da mercadoria, assim como o fetiche das novas tecnologias que fundamentam a atual sociedade das ilusões? (DUARTE, 2003). Como instrumento para o desvelamento do caráter nebuloso da sociabilidade atual, ancorada no mercado e na ordem capitalista, Saviani defende a tese do "trabalho como princípio educativo" (DUARTE \& SAVIANI, 2012, p. 173). Assevera Saviani:

[...] quando consideramos o trabalho como princípio educativo, estamos querendo dizer que o trabalho, enquanto elemento fundante $\mathrm{e}$ 
determinante da vida humana em seu conjunto é, por consequência, fundante e determinante da educação. Ou seja: uma vez que o trabalho é "condição natural eterna da vida humana", em qualquer sociedade o trabalho se comporta como principio educativo, isto é, determina a forma como é construída e organizada a educação. Logo, também na sociedade capitalista na qual o trabalho assume a forma da unidade de valor de uso e valor de troca, nos termos do próprio Marx (idem, p. 175).

É muito oportuno em tempos "pós-modernos", em que o trabalho tem sido questionado como categoria analítica ${ }^{6}$, resgatar sua centralidade como principio educativo. Tal princípio diferencia a postura marxista das demais posições em relação à educação, uma vez que: "[...] sem se considerar o trabalho e a forma concreta pela qual ele define o modo de produção da vida humana numa situação histórica determinada, não será possível entender a forma assumida pela educação na referida situação histórica" (idem).

O objetivo aqui não é apresentar os fundamentos marxistas da tese do trabalho como princípio educativo, tarefa imprescindível, já que mesmo setores marxistas têm se posicionado criticamente a esse fundamento da pedagogia histórico-crítica. Nosso objetivo é destacar o papel estratégico que assume essa tese, uma vez que afirmar que o trabalho é um principio educativo: "[...] significa tomá-lo como referência para se organizar a educação de maneira contra-hegemônica procurando articulá-la com o movimento revolucionário de superação do capitalismo" (DUARTE \& SAVIANI, 2012, p. 178-79).

A prática social, ponto de partida e de chegada da pedagogia histórico-crítica, está inserida nas relações sociais de produção. Estas, por sua vez, para serem dominadas necessitam ter sua base concreta desmistificada, compreendida como resultado do desenvolvimento das forças produtivas. Se o materialismo histórico-dialético é um antídoto á fragmentação "pós-moderna", o trabalho como princípio educativo nos permite explicitar como a ciência se converte em potência material no processo de produção, o que requer não somente o domínio teórico, mas também o domínio prático da articulação do saber ao processo produtivo (idem, p. 180).

A perspectiva que se delineia a parti daí é o desenvolvimento da capacidade dirigente daqueles que se propõe à tarefa histórica da transformação social. Para tanto, é necessário desmistificar também a divisão social do trabalho sobre a égide do capital, superando as objetivações genéricas em si nele fundamentadas, através das objetivações genéricas para si, constituídas pela ciência, pela arte pela filosofia, pela moral e pela política, que, diferentemente das primeiras, se encontram nos âmbitos não-cotidianos da atividade social (DUARTE, 2007, p. 33).

\section{Considerações finais}

Discorremos neste texto sobre a importância intelectual de Dermeval Saviani para o pensamento social, político e pedagógico brasileiro. Entendemos tratar-se de um pensador que desde seus primeiros passos como educador e pesquisador ousou apresentar, mesmo em tempos sombrios de nossa história, na contracorrente das teses conservadoras existentes no pensamento pedagógico, uma proposta pedagógica que, criticando o modismo escolanovista, não abandonou a escola como espaço de luta. Desde então, Saviani tem nos brindado com sua vasta produção teórica, que além de crítica nos possibilita pensar uma estratégia de transformação social à qual deve servir a escola pública.

Trata-se, portanto, de um intelectual comprometido com a transformação social, posicionando-se sempre na defesa de uma sociedade justa e igualitária. Sua trajetória de vida é exemplo de persistência e trabalho acadêmico rigoroso, consolidando-se suas obras 
a cada interstício não somente como clássicos da educação, mas verdadeiros instrumentos de luta daqueles que não se acomodam diante dos desafios colocados à transformação social.

Mais do que gastar seus esforços com análises exegéticas que, apesar de importantes, ao serem mal manuseadas esterilizam a obra marxiana, Saviani assumiu a tarefa propugnada por Marx junto ao Conselho Geral da Associação Internacional dos Trabalhadores: "[...] Por um lado, é necessário modificar as condições sociais para criar um novo sistema de ensino; por outro, falta um sistema de ensino novo para poder modificar as condições atuais. Consequentemente, é necessário partir da situação atual" (MARX \& ENGELS, p. 96).

Tal assertiva marxiana implica aos setores que se identificam com os interesses da classe trabalhadora mais do que a proposição de uma "educação para além do capital". É necessário, seguindo as trilhas apontadas por Gramsci, entrar na fase clássica que, no caso da educação, corresponde à transmissão-assimilação do saber sistematizado (2008, p. 18). Uma educação para além do capital requer um instrumento teórico para a fundamentação de sua prática. Não é outro o papel assumido pela pedagogia histórico-crítica de Dermeval Saviani.

\section{Referências:}

ANTUNES, Ricardo. Adeus ao trabalho?: ensaio sobre as metamorfoses e a centralidade do mundo do trabalho. $8^{\text {a }}$ ed. São Paulo: Cortez; Campinas-SP: Editora da Unicamp, 2002.

Os sentidos do trabalho. $7^{\mathrm{a}}$ reimpressão, São Paulo: Boitempo, 2005.

BATISTA, Eraldo L.; LIMA, Marcos R.. A pedagogia histórico-crítica como teoria pedagógica transformadora: da consciência filosófica a pratica revolucionária. In. Pedagogia histórico-critica: desafios e perspectivas para uma prática transformadora. Campinas: Autores Associados, 2012.

DUARTE, Newton. Sociedade do conhecimento ou sociedade das ilusões? Campinas-SP: Autores Associados, 2003.

Educação escolar, teoria do cotidiano e a Escola de Vigotski. $4^{\mathrm{a}}$ ed. Campinas: Autores Associados, 2007.

DUARTE, Newton \& SAVIANI, Dermeval (orgs.) Pedagogia histórico-critica e luta de classes na educação escolar. Campinas-SP: Autores Associados, 2012.

GRAMSCI, Antonio. Cadernos do cárcere. (Vol. 1). Rio de Janeiro: Civilização Brasileira, 2006a.

Cadernos do cárcere. $4^{\mathrm{a}}$ ed. (vol. 2). Rio de Janeiro: Civilização Brasileira, $2006 \mathrm{~b}$.

MARTINS, Ligia Marcia. Pedagogia histórico-crítica e psicologia histórico-cultural. In: MARSIGLIA, Ana Carolina G. Pedagogia Histórico-Crítica: 30 anos. Campinas, Autores Associados, 2011.

MARX, Karl. Grundrisse. São Paulo: Boitempo: Rio de Janeiro: Ed. UFRJ, 2011.

SAVIANI, Dermeval. Educação e questões da atualidade. São Paulo: Cortez, 1991.

Pedagogia histórico-crítica: primeiras aproximações, $10^{\mathrm{a}}$ ed. rev. Campinas: Autores Associados, 2008.

Escola e democracia. 41. Ed Campinas, Autores Associados, 2009a. 
Educação: do senso comum à consciência filosófica. $18^{\mathrm{a}}$ ed. Campinas-SP: Autores Associados, 2009b.

WOOD, Ellen M. Democracia contra capitalismo: a renovação do materialismo histórico. $1^{\mathrm{a}}$ reimpressão. São Paulo: Boitempo, 2006.

\section{Notas:}

${ }^{1}$ Doutor em Educação pela UNICAMP e membro do Grupo de Estudos e Pesquisas - HISTEDBR. E-mail: eraldo_batista@ hotmail.com.

${ }^{2}$ Mestre em Educação pela UNICAMP e membro do Grupo de Estudos e Pesquisas - HISTEDBR. E-mail: lima2782@terra.com.br.

${ }^{1}$ Destacou-se a participação efetiva de frades dominicanos na resistência à repressão, apoiando sistematicamente as lideranças de esquerda e as tendências revolucionárias na defesa da democracia e dos direitos humanos. Também as comunidades eclesiais de base (CEB) tornaram-se um espaço de reunião, reflexão e organização de diferentes lutas por moradia, creche, saúde e melhores condições de vida nas periferias das grandes cidades. Além da Pastoral Operária (PO), que durante a década de 1970 destacou-se como instrumento de organização da classe trabalhadora, ajudando a formar grande parte das lideranças que deram origem ao "novo sindicalismo", rompendo com o "peleguismo" que predominava na estrutura sindical desde a Era Vargas.

${ }^{2}$ Apesar de reconhecer a importância do trabalho administrativo, Saviani nunca foi afeito a cargos burocráticos. Nas poucas vezes em que assumiu compromissos dessa ordem, o fez em solidariedade ao conjunto com o qual desenvolvia o trabalho docente, seja na PUC-SP, UFSCar, UNIMEP e, por fim, UNICAMP (Projeto Memória Viva - Centro de Memória da Educação da FE-Unicamp).

${ }^{3}$ Com o Golpe de 1964, a pedagogia nova perdeu espaço junto ao aparelho burocrático de Estado, o que levou ao desenvolvimento de uma "Escola Nova Popular", destacando-se a pedagogia freireana como uma de suas expressões mais significativas. Assim, ganhou hegemonia junto aos militares a pedagogia tecnicista, fundamentada no pressuposto da neutralidade cientifica inspirada nos princípios da racionalidade, eficiência e produtividade, reordenando o processo educativo de forma a torná-lo objetivo e operacional (SAVIANI, 2009, p. 11).

${ }^{4}$ Como sugere a organização no segundo semestre de 2012 da disciplina Pedagogia histórico-crítica: uma construção coletiva, tornando-se a principal referência teórica do grupo de pesquisa HISTEDBR.

${ }^{5}$ Buscando a superação de sua crise estrutural e a recuperação de seu ciclo reprodutivo, abalado pela conflitualidade do trabalho, o capital colocou em curso várias transformações no processo produtivo, que em linhas gerais se caracterizam por formas flexíveis de acumulação que têm por objetivo controlar as lutas sociais por meio de formas de gestão descentralizadas, fundamentadas na participação manipuladora dos trabalhadores, aprofundando, assim, as condições do trabalho alienado e estranhado (ANTUNES, 2005, p. 52).

${ }^{6}$ Como observa Antunes, um prolongamento analítico e político do questionamento da centralidade do trabalho é a perda da potencialidade contestadora da classe trabalhadora e de sua capacidade de transformação da ordem capitalista, tese essa coerente com o ideário "pós-moderno" (ANTUNES, 2002, p. 9).

Recebido em setembro-13

Aprovado em novembro-13 